\title{
Research Summary of College English Micro-lecture in China*
}

\author{
Yan $\mathrm{Wu}$ \\ College of Humanities and Social Sciences, Heilongjiang Bayi Agricultural University, Daqing, China

\begin{abstract}
With the development of information technology, micro-lecture has gradually become the focus in the field of education and aroused extensive attention from educators. It will become a new kind of teaching mode and an approach to learning. Mobile learning, distance learning and online learning which based on the micro-lecture will be more and more popular in education. In this paper, the articles in the aspects of theories and practices of college English micro-lecture were summarized to provide some referential information for college English teaching reform.
\end{abstract}

Index Terms-micro-lecture, College English, The Flipped Classroom

\section{INTRODUCTION}

In the Information Age, the traditional college English teaching faces tremendous challenges. As a new teaching material, the micro-lecture is widely used in college English teaching in China, because of its advantages: conciseness, abundant resources, easy interaction, mobility, etc. In order to improve the efficiency of teaching and learning, teachers usually use micro-lectures which are short videos with no more than 10 minutes for a certain knowledge point or some kind of micro skills in teaching. Micro-lecture is not a complete teaching process, just a part of teaching. As a means of blended learning, students could learn knowledge whenever they want. And it can break through the limitations of traditional college English teaching.

As a new teaching method with great potential for development, micro-course has become a hot topic in the field of college English information-based teaching, and researchers have studied it from various angles. At present, the research results are developing in the direction of actual teaching and integration, which is of great guiding significance to the first-line teaching. However, most of the researchers carried out research based on subjective ideas with strong personal preference. Therefore, this paper summarizes research status and development trend of college English micro-lecture to provide reference for college English education.

\section{BASIC ANALYSIS OF LITERATURE}

Originated in the United States, micro-lecture has been introduced to China in 2010 and quickly became popular in the field of education. The articles were searched by key words "micro-lecture" and "college English" on CNKI ( China National Knowledge Infrastructure) to select 711 documents including 11 master's theses and 8 conference articles that the unrelated articles were cut out according to the correlation from January 1,2013 to December 20,2017.

A. Analysis of Post Trend of Articles

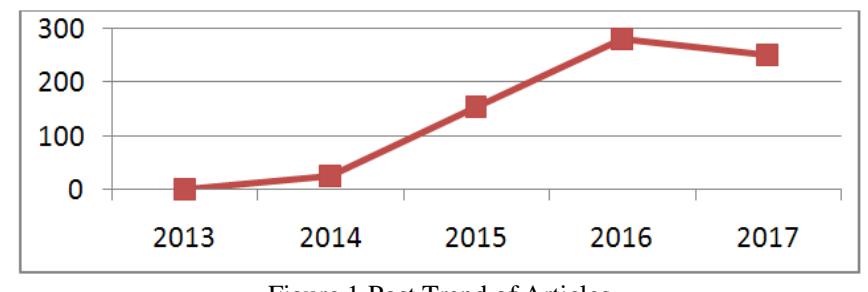

Figure 1 Post Trend of Articles

Figure 1 depicts the trend of research articles on college English micro-lecture in nearly five years. Compared with the study on micro-lecture in China since 2011, the research into micro-lecture of college English was two years late. In 2013, the number of published paper was only one. From 2014, micro-lecture has been gradually pay attention in college English teaching. The most obvious rise is in 2016 and in 2017 which means that the research on micro-lecture has been the attention of teachers and researchers in college English teaching.

Based on the data in figure 1 and the Price Law of scientific and technological literature analysis, it can be deduced

\footnotetext{
* This study is funded by the projects "Research on the Flipped Classroom Based on College English Micro-lecture", project No. GJB1215052 and "the Cultivation of English Language Ability for Students Majoring in Agriculture", project No. 16G187
} 
that the research on college English micro-lecture is in a high-speed development period.

B. Analysis of the Number of Articles in Each University

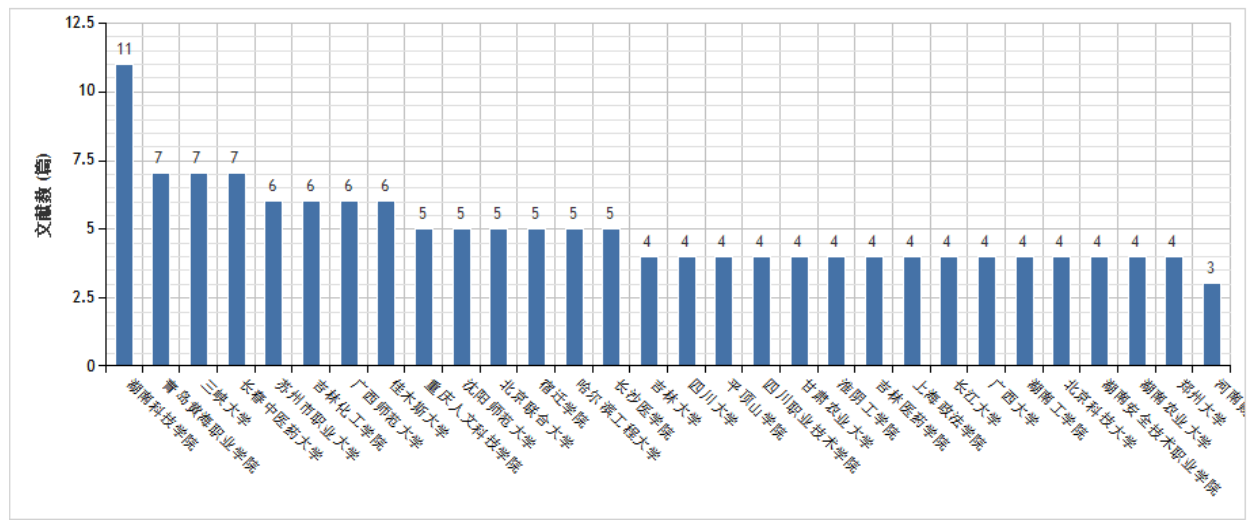

Figure 2 the Number of Articles in Each University

Figure 2 is the paper quantity of each college or university (part of them). Hunan University of Science and Engineering was 11 and won the first place in numbers. Qingdao Huanghai University, China Three Gorges University and Changchun University of Chinese Medicine tied for the second place. Among the top 14 universities, there are 8 comprehensive universities, 2 normal universities, 2 universities of science and technology and 2 medical universities. Thus, researchers and teachers are from various universities and colleges which fully show that micro-lecture has been attracting increasing attention in college English teaching in China. Most of the papers were the research results supported by education scientific research fund. The rise of research on college English micro-lecture and its in-depth study cannot be separated from the support and promotion of education administration department.

\section{Analysis of Source of Literature}
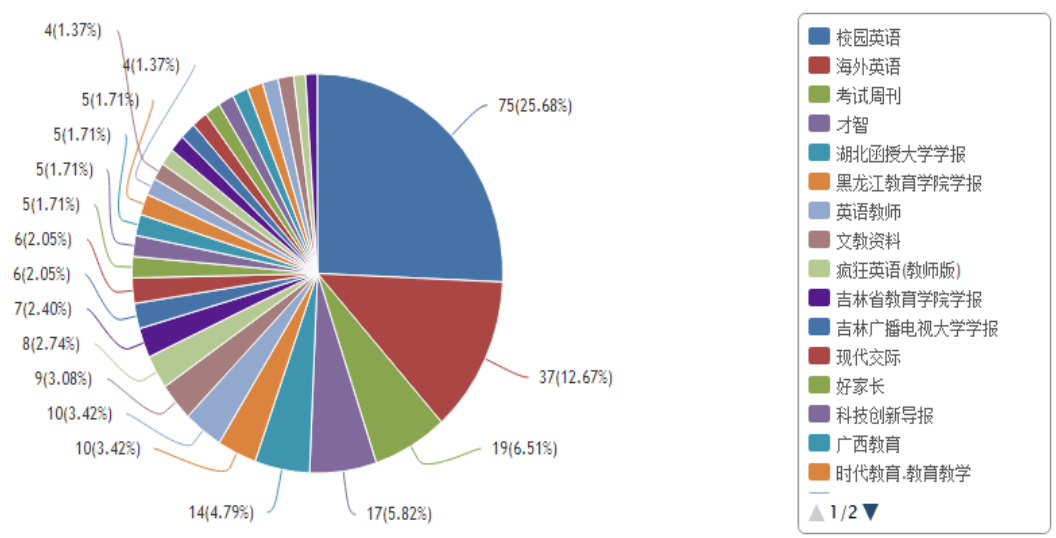

Figure 3 Source of literature

The total amount of articles has been increasing rapidly in the past five years. It can be found from the figure 3 that most of the papers were published on the education periodicals, especially those in English education. For example, English on Campus 25.68\%, Overseas English 12.67\%, Exam Weekly 6.51\%, Ability and Wisdom 5.82\%. Some papers were included by college journals, such as, Journal of Hubei Correspondence University 4.79\%, Journal of Heilongjiang College of Education 3.42\%, and Journal of Education Institution of Jilin Providence 2.4\%. However, the quantity of articles published in other kind of journals is relatively low. The core journals have fewer publications, 2 articles in 2014, 8 articles in 2015, 10 articles in 2016, and 5 articles in 2017, accounting for 3.5\% of the total volume. Micro-lecture has become a hot topic in college English teaching, but overall, the number of high level articles is less and the quality of the research is not high.

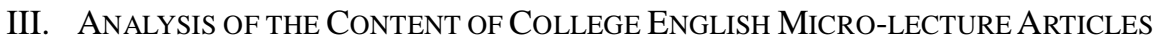

The contents of research are expected to mature gradually which vary from the study on definition and theories to the course development, curriculum design, construction and application, and so on.

According to the statistical analysis of 711 samples, it was found that the study of micro-lecture of college English mainly consisted of six major categories and then they were divided into 19 sub-categories based on the emphasis of the research contents. The same articles will overlap in different categories. Through the classification, comparison and 
study of the sample documents, the contents of the research on college English micro-lecture mainly involves two aspects. The first part is the basic theoretical research on micro-lecture including its development history, connotation, meaning and characteristics, and so on. The other part is the practical application containing its designing construction, application in teaching, etc.

TABLE 1

CONTENT CLASSIFICATION OF COLLEGE ENGLISH MICRO-LECTURE

\begin{tabular}{|c|c|c|c|}
\hline category & category & Number of articles & Percentage \\
\hline \multirow{7}{*}{ basic research } & concept \& characteristics & 403 & $56.7 \%$ \\
\hline & basic theory & 64 & $9 \%$ \\
\hline & significance & 131 & $18.4 \%$ \\
\hline & literature review & 58 & $8.2 \%$ \\
\hline & development tendency & 23 & $3.2 \%$ \\
\hline & feasibility analysis & 67 & $9.4 \%$ \\
\hline & situation of college English teaching & 162 & $22.8 \%$ \\
\hline \multirow{2}{*}{ technology } & internet & 16 & $2.3 \%$ \\
\hline & mobile learning & 6 & $0.8 \%$ \\
\hline \multirow{2}{*}{ Resource construction } & The construction of resource database & 2 & $0.3 \%$ \\
\hline & The construction of platform & 10 & $1.4 \%$ \\
\hline \multirow{6}{*}{$\begin{array}{l}\text { research on application and } \\
\text { practice }\end{array}$} & teaching design & 269 & $37.8 \%$ \\
\hline & teaching reflection & 97 & $13.6 \%$ \\
\hline & designing of micro-lecture & 66 & $9.3 \%$ \\
\hline & the flipped classroom & 214 & $30.1 \%$ \\
\hline & teacher training & 28 & $3.9 \%$ \\
\hline & course teaching & 83 & $11.7 \%$ \\
\hline evaluation & & 9 & $1.3 \%$ \\
\hline analysis of competition product & & 8 & $1.1 \%$ \\
\hline
\end{tabular}

The specific distribution of all kinds of articles is shown in table 1. The research in each field of micro-lecture is involved, but the development is unbalanced in general. The number of articles about basic theory, designing and application of micro-lecture accounts for a large part of all papers. And the number of related technology and evaluation standard is very few, especially the research on micro-lecture evaluation standard. Therefore, the future direction of research about college English micro-lecture can be carried out based on the relevant technology and evaluation criteria.

In terms of research contents, the articles have their own focus. In order to better display the research status about college English micro-lecture in recent years, this paper discusses it from four parts: basic research, technical research, applied research and evaluation standard.

\section{A. Basic Research on College English Micro-lecture}

According to the theme and contents, the basic research on college English micro-lecture can be divided into the concept of micro-lecture, theoretical research, literature review, development trend and feasibility analysis, etc.

The number of research achievements in each category is shown in table 1. They represent the following characteristics:

(1) Most of the articles have clarified the concepts, meaning, characteristics, essence and influence of micro-lecture. 56.7 percent of the articles discussed the definition and characteristics of micro-lecture. It can be predicted that researchers' understanding of micro-lecture has been more comprehensive and in-depth.

(2) There are fewer articles (only 9\%) on the theories of micro-lecture. Some related theories on teaching and curriculum design of micro-lecture were mentioned in these articles. For example, multimodal discourse analysis $(8$ articles), 6 articles from the perspective of cognitive linguistics, 5 articles on independent learning theory, and 4 constructivism articles. Other theories include second language acquisition, connectionism, output driving hypothesis and schema theory, etc. Some articles refer to the relationship between micro-lecture and MOOC and the flipped classroom, which is a new kind of teaching method based on constructivism in the internet era. In general, there are no systematic theoretical frameworks and no consistent and authoritative opinion on the learning theory and teaching thought involved in micro-lecture.

(3) $22.8 \%$ of the articles are about the summary and analysis of the current situation of college English teaching in China. At present, the shortcomings of Chinese college English teaching are inadequate teaching equipment, improper teaching methods, monotonous teaching mode and boring activities in class. Students lack the opportunities to deepen understanding and output language through discussion. They also cannot get effective feedback on their learning from teachers. Thus, we should vigorously promote the integration of information technology and teaching.

(4) There are $9.4 \%$ of the articles on the feasibility analysis of college English micro-lecture. These articles discussed the feasibility of micro-lecture in college English teaching from the aspects of teachers' team, students' learning characteristics, teaching environment and the present college English teaching mode respectively.

College English teachers with high degree and cultural level, they have the strong learning abilities to the information technology to apply the micro-lecture in college English teaching. With the in-depth reform of education, many college students are no longer satisfied with the traditional teaching mode, instead, most of them expect that they can choose to 
learn knowledge that they are weak and interested in through autonomous learning. The flipped classroom teaching mode based on micro-lecture can meet the students' demand and stimulate their interests in learning. From the point of development of information technology and teaching reform, the application of micro-lecture in college English teaching is feasible. Micro-lecture can solve the problems of learning in time and space. Most of articles about the feasibility analysis of micro-lecture applied in college English teaching concentrated on information resources and development of regional education information resources. However, the other feasibilities about it need us to explore and discover.

(5) There are relatively fewer articles on the literature review and the trend of development of micro-lecture. Beginning from 2013, the development and related research of college English micro-lecture are relatively short. So far, there are quite a few numbers of relevant articles.

\section{B. Research on Related Technology and Resource Construction of College English Micro-lecture}

Articles on related technologies of micro-lecture are fewer. Most of them about the construction of technical platform or curriculum construction of college English micro-lecture, the combination of network and mobile learning with micro-lecture applied in college English teaching. Therefore, it is necessary to pursue further study and develop the related technologies of micro-lecture.

\section{The Application and Practical Research on College English Micro-lecture}

There are many articles about the application of micro-lecture in college English teaching. For instance, some are about thoughts on some problems of various contests of micro-lecture, some are concerned about the design of micro-lecture. And the teaching mode and strategy of college English micro-lecture are considered. In general, there is no mature application mode for how to better apply the micro-lecture to the college English class and achieve better teaching effect.

1. Instructional design and reflection of micro-lecture

About $37.8 \%$ of articles refer to the strategies, methods and approaches to the college English micro-lecture, including the design and arrangement of pre-class review, new course introduction, teaching emphasis, homework and exercises, etc.

Many teachers reflected on it in various aspects. The micro-lecture is short, brief, limited in length. When faced with the complex logical knowledge, its learning effect will be inferior to other teaching modes. Knowledge of phonetics, vocabulary, and grammar is relatively independent which is suitable for making micro-lecture. In comparison, paragraphs and chapters are large and complex which require learners more time to study and are unfit for micro-lecture. It presents more challenges for teachers. In order to make and design micro-lecture, teachers need more information and time to prepare lessons. Teachers have become the main body of co-learning to help students to choose content, to use the right learning methods and to complete the learning effect evaluation, etc.

The quality of micro-lecture needs to be improved. Although its characteristics are fragment, the integration and systematization should be concerned in the teaching application. It can be flexibly applied in all aspects of college English teaching, such as, preview, introduction of new knowledge, exercises, expansion of the text. As a new kind of teaching resource, it can be an efficient and convenient assistant means of teaching. It can save the teaching time and be watched repeatedly. Learning it, students have a large autonomous space so that they can study deeply and develop their abilities to discover, analyze and solve the problems in the process of learning.

2. The design and production of micro-lecture

The articles involved in the design and production of college English micro-lecture were 9.3\%. Through reading the articles, there are some main problems in its production.

(1) Some teachers without relevant education technology training and no consciousness and abilities of writing script, but directly design the micro-lecture according to the teaching plans. In this way, the college English micro-lectures have some problems, such as lacking of relevant designing script, no outstanding teaching focus, unsophisticated content, no prominent the interaction between teachers and students in classroom activities.

(2) Most of the micro-lectures are simple and low technology and resources are unevenly distributed. At present, the development and resource distribution of education in China are seriously unbalanced, which is restricted by many technical conditions of education.

(3) The design of college English micro-lecture focuses on the presentation of the learning content and ignores the integration with the real class and the learning process. In the future, the design of it will no longer focus on the content, but pay more attention to the design of learning activities.

3. Research on the teaching mode of college English micro-lecture 


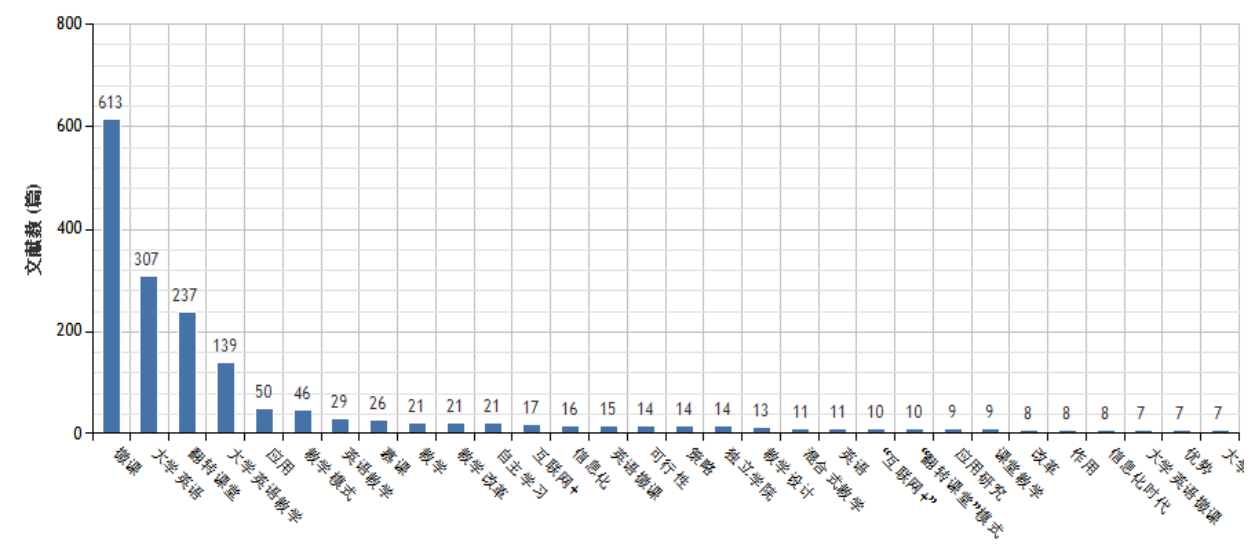

Figure 4 distributions of key words

"The flipped classroom" as a teaching mode which based on the "micro-lecture", the new teaching resources, has been widely applied in western countries. Whether and how they can be applied in Chinese college English teaching has gradually become the focus of domestic foreign language teachers. From the figure 4, we can see that "micro-lecture", "college English", "the flipped classroom" and "college English teaching" are the high-frequency words used in the articles. $30.1 \%$ of the articles discussed the application of the flipped classroom based on micro-lecture in college English teaching. A set of teaching modes suitable for college English has been gradually formed under the teachers' unremitting efforts. And 24 articles of them mentioned other platforms to mix it with MOOC, Wechat, Unipus, micro blog, etc.

For teachers, the combination of micro-lecture and the flipped classroom will change the traditional teaching methods. The teachers' teaching plan, class activities, or the teaching reflection after class will be more pertinence and effectiveness. For students, it can meet their needs to realize the individualized learning to choose knowledge on-demand, as well as can strengthen knowledge and speed up the process of knowledge internalization.

4. Teacher training

The research and application of micro-lecture have a profound influence on the college English staff. First, it can improve the teachers' abilities to teach and research. Secondly, teachers' teaching concept and innovation consciousness can be strengthened. Thirdly, it can promote teachers to learn and apply information technology in teaching.

Researches on college English micro-lecture arouse teachers' enthusiasm for work and create an academic atmosphere with competition and cooperation. There are some significance proposed by researchers to strengthen teaching staff under the background of micro-lecture. The resources of micro-lecture as the supplement can solve the shortage of teachers. As the driving force, researchers on college English micro-lecture will improve academic level of teachers. Taking the construction of micro-lectures as an opportunity, teachers can change their teaching ideas and renew the knowledge and learn the advanced information technologies. The design of it will promote the diversity of teaching modes and methods of college English teaching. The creation of micro-lecture platform can realize the standardization of the evaluation system of college English teaching.

5. Course teaching

Designing and application with specific subjects and skills are the mainstream of study on college English micro-lecture. There are 38 articles applied the micro-lecture in the courses of listening and speaking, 15articles of reading, 13 articles of writing and 7 about cultural introduction, as well as grammar, translation, ESP, EAP and expanding courses. It can be perceived that the micro-lecture is widely used in the courses of college English.

\section{Evaluation Standard}

In the lecture "Application of Micro-lecture in Foreign Language Teaching: Principles, Design and Evaluation” held by National Research Centre for Foreign Language Education in October 2014, Professor Wen (Wen Qiufang) presented evaluation of college English micro-lecture from five aspects: language, teaching methods, teaching goals, procedures and topics. The language should be brief, standardization and infectious. The designing method is clear, original and vivid in concept. The setting goals of micro-lecture should meet the teaching characteristics and requirements to maximize the teaching effectiveness. Its teaching process should be simple and comprehensive. The selected topic should be small and refined. Teachers can design and reform the college English micro-lecture according to this evaluation standard. 9 articles of all refer to the evaluation standard of college English micro-lecture. Wan Min (2014) mentioned process evaluation and termination evaluation in her paper A Study on Flipped Classroom Model in College English Teaching. In her paper, she mentioned that the evaluation of teaching effect was mainly carried out in two forms: process assessment and summative assessment. In the process assessment, the main part was students' self-assessment in the form of questionnaire to their learning effect. Its contents mainly include the knowledge of learning, learning process and learning attitude. The summative assessment adopted the methods of final course and proficiency level examination. Guo Da-min (2016) in his The Practical Research of College English Micro-lecture 
Teaching discussed multiple monitoring and evaluation system of independent study. The multiple monitoring and evaluation system of independent study is composed of several modules, including teachers' teaching monitoring, surveillance technology and self-monitoring, at the same time it can also according to student's attitude to adjust in time, to find the most effective learning strategies, so as to achieve the desired learning effect. The establishment of evaluation system is mainly to assess student's learning process and learning results. The evaluation can be a formative assessment, and can also be summative assessment, in the aspects of the students' learning attitude, learning methods, learning efficiency, and others.

\section{The Factors That AfFect the DeVelopment And ApPliCATion OF Micro-lecture}

In his article the Misunderstanding and Development Suggestion of Micro-lecture Construction, Hu Tie-sheng (2014) pointed out some misunderstanding in the construction of Micro-lecture in China. For instance, quite a few teachers have not enough knowledge of the essential features of micro-lecture. Teachers generally focus on making technology of micro-lecture and neglect its innovation of teaching design and teaching implementation process. The resources of existing micro-lectures are single. The micro-lecture platform is relatively backward, and learners have a single use mode for the existing micro-lectures. Most of the learners were only watching, and the comprehensive performance of the micro-lectures did not bring into play. The number of it is much, but scattered distribution. The material does not match with the textbook. There is no special, thematic and serialized micro-lecture system. New ways of studying based on micro-lecture such as mobile learning, the flipped classroom and blended learning are far from universal. As a new thing, micro-lecture is still in the construction stage, and its propaganda is not enough.

It can be summarized some factors influencing the application of college English micro-lecture through researching the articles on it. Firstly, teachers and students are weak in accepting the new technology. Because the traditional education is deeply rooted in their minds, they have poor awareness of advantages of micro-lecture. Secondly, many teachers think that micro-lecture will increase their workload and some students with poor self-control are not interested in learning micro-lecture. Thirdly, some teachers do not master the technologies of producing micro-lecture. Teachers need to be trained on the production and application of micro-lecture. The design of it doesn't deeply integrate with the class. Fourthly, the resources of micro-lecture are single, unsystematic and lacking of excellent lectures, deficiency in uniform plan. Its utilization efficiency is low. The system and mechanism of evaluation are not perfect. Its platform is relatively backward and cannot serve the teaching well.

\section{CONCLUSION}

Micro-lecture, a new type of online teaching method, provides a vast teaching and learning space for English teachers and students in colleges and universities in China. Its purpose should be to improve the students' English level and the teaching skills of teachers. The teaching process has become the embodiment of the teaching concepts and the integration of a variety of resources. It will bring challenges and opportunities to college English teaching. It is of great significance to develop students' subjective initiative and innovative spirit and explore their learning potential by using the characteristics of "micro-lecture" and improving the College English teaching mode in China.

The research on college English micro-lecture in China is relatively late and develops rapidly in the last two years. Most experts and scholars have studied its basic theories, design and application. Relatively speaking, the studies on its relevant technologies and evaluation standards are not enough. And the latter needs to be further studied. Through the study on the articles about college English micro-lecture, it is found that the research on it in China is becoming more and more concentrated in the field of application. There is still a very large research space of its application. And we need to make further and targeted research to promote it. Micro-lecture is a trend and direction learning in the future. As a new teaching mode, it will definitely bring more influence to college English teaching.

\section{REFERENCES}

[1] Guo Da-min. (2016). The Practical Research of College English Micro-lecture Teaching. Journal of Taiyuan Urban Vocational College 8, 94-95.

[2] Hu Tie-sheng. (2014). The Misunderstanding and Development Suggestion of Micro-lecture Construction. Educational Information Technology 5,33-34.

[3] Hu Tie-sheng. (2014). Current Situation Analysis and Development Strategies of the Micro-lecture Construction in Universities. Modern Educational Technology 2, 5-13.

[4] Liang Wen. (2016). The Application of the Micro-lecture Environment in Chinese English Teaching. Researches on Higher Education 2, 162-164.

[5] Lu Hai-yan (2014). Feasibility Analysis on the Application of Micro-class Based "Flipped Classroom" Mode in College English Teaching. Technology Enhanced Foreign Language Education 6,33-36.

[6] Rao Hua-hong. (2015). Study and Practice of Flipped Classroom in College English Teaching. Overseas English 12, 61-63.

[7] Wan Min. (2016). A Study on Flipped Classroom Model in College English Teaching. Higher Education Exploration 5, $69-72$.

[8] Wang Feng. (2016). Research on the Application of Micro-lecture to college English Teaching. Theory and Practice of Education 9, 47-48.

[9] Yan Yan. (2014). Research on Teaching Strategies of College English Micro-lecture. Journal of Green Science and Technology 
12,288-289.

[10] Yang Yong-lin. (2014). Using Big Data in the Teaching of English Writing in the MOOC and SPOC Era. Modern Education Technology 12, 45-51.

[11] Zhao Jun-fang. (2016). The Current Situation Research on Flip Classroom in China: Hot Spots and Tendency. University Education Science 9, 82-88

[12] Zhang Xiao-hui. (2016). Application of Flipped Classroom Teaching Mode in College English Teaching. Heilongjiang Researches on Higher Education 11,156-159

[13] Zhang Yun-qing. (2014). Practice and Research on Micro-lecture of College English Teaching. Journal of Shaoguan University 3,189-192.

[14] Zhou Xiao-ling. (2016). Research on the Application of the Flipped Classroom Teaching Model in College English Teaching. Journal of Guangxi Normal University 10,131-138.

[15] Zhu Jing. (2015). The Construction and Application of Micro-class Mode of Instruction-With a Focus on College English Visual-aural-oral Course. Technology Enhanced Foreign Language Education 9, 21-25.

Yan Wu was born in Songyuan, Jilin Province, China in 1980. She received her Master's degree in linguistics from Harbin Normal University in 2011. Her research interests include applied linguistics and foreign language teaching. 